\title{
Factors affecting the uptake of prenatal diagnosis for sickle cell disease
}

\author{
Mary Petrou, Maura Brugiatelli, R H T Ward, Bernadette Modell
}

\begin{abstract}
Between 1979 and 1990, 170 couples at risk of having children with sickle cell disease, resident in the $U K$ and with a continuing pregnancy, were referred for counselling at the University College Hospital Perinatal Centre. Approximately $50 \%$ of the couples, including those where one partner actually had sickle cell disease, requested prenatal diagnosis. This was requested in $82 \%$ of pregnancies when the mother was seen in the first trimester of pregnancy and in $49 \%$ when she was seen in the second trimester. More than $\mathbf{9 0 \%}$ of referred couples who already had an affected child requested prenatal diagnosis. The type of sickle cell disease involved and ethnic group also influenced choice. These results show the importance of detecting and counselling couples at risk before pregnancy whenever possible.
\end{abstract}

( $\mathcal{F}$ Med Genet 1992;29:820-3)

The objective of screening for carriers of recessively inherited diseases is to inform them of possible genetic risk, and to allow couples who actually are at risk an informed choice among the available options. ${ }^{1}$ These include prenatal diagnosis. Carrier screening for haemoglobin disorders (the thalassaemias and sickle cell disease) is now standard practice in antenatal clinics in the UK. ${ }^{2}$ When a carrier woman is detected, her partner is invited to come for testing: if he also carries a haemoglobinopathy trait, the couple may be at risk. Couples where both partners are carriers have a $25 \%$ risk of an affected infant in each pregnancy: couples where one has a major (homozygous) disorder and one is a carrier have a $50 \%$ risk.

Most couples at risk for having children with $\alpha$ or $\beta$ thalassaemia major choose prenatal diagnosis and selective abortion of affected fetuses. ${ }^{34}$ By contrast, the decision for or against prenatal diagnosis for sickle cell disease can be very difficult, as it includes a range of conditions of variable and unpredictable severity. Sickle cell anaemia (Hb SS) and $\mathrm{Hb}$ SD disease are usually the most severe, haemoglobin $S / \beta$ thalassaemia is usually intermediate, and $\mathrm{Hb} \mathrm{SC}$ disease is usually the mildest. ${ }^{56}$ Clearly, couples at risk require expert counselling.

The availability and quality of counselling for risk of sickle cell disease has been improving steadily in the UK since training courses were started at the Brent sickle cell centre in 1981, and subsequently at other centres. Cur- rently, countrywide, 35 trained counsellors are working in 23 Health Authorities, 12 of them in six Health Authorities in North London (E Anionwu, personal communication). In England and the United States, about a third to a half of at risk couples counselled by a trained person request prenatal diagnosis. ${ }^{78}$ This suggests that a review of a series of cases may cast light on factors that influence the choices informed couples make. Here we report the results of a review of the records of pregnant women at risk for having children with sickle cell disease counselled at the UCH Perinatal Centre, which offers a regional and national service for prenatal diagnosis of haemoglobin disorders. The results show that choice is influenced by the nature of the genetic risk, ethnic group, experience of an affected family member, and the possibility of diagnosis in the first trimester of pregnancy. Clearly, couples at risk for having children with inherited diseases should be identified and provided with expert counselling either before or at the earliest possible stage of pregnancy.

\section{Methods}

From 1979 to the end of 1990, 170 couples resident in the UK and at risk for having children with sickle cell disease attended the Perinatal Centre at University College Hospital for counselling and the offer of prenatal diagnosis. Almost all were resident in the North-East or North-West Thames Regions, though many of African extraction were long term visitors for educational purposes, and primarily resident in Africa. All the women were already pregnant: most were seen within a few days of referral and all within a week. All were seen by one of two counsellors (MP or BM) who have a very similar approach. The additional risk of miscarriage associated with chorionic villus sampling (CVS) or fetal blood sampling at our centre is given as 1 to $2 \%$. Written information is provided at the end of the session (copies available on request from Dr Petrou), and objectivity is ensured by putting couples in touch with support associations (for example, the Sickle Cell Society) and providing publications produced or approved by the associations. Standard notes kept for each couple seen include the information provided by the referring centre, ethnic group, week of gestation when the woman was first seen, results of subsequent investigations, details of how and when the couple found they were carriers and heard of prenatal diagnosis, full obstetric history, and details of the choice made (with reasons when given), as well as 
details of each prenatal diagnosis. This information set was complete for most, but not all, cases. The data available were tabulated on a yearly basis.

\section{Results}

Table 1 shows that the annual number of referrals of couples at risk for sickle cell disease is rising steadily. There were very few before first trimester prenatal diagnosis was introduced in 1982 to 1984 , and there has been a steady increase since 1988, as trained counsellors have become available in the North-West and North-East Thames Regions. Fifty-two percent of the couples seen requested prenatal diagnosis, and there has been no clear change in this proportion with time. A majority of these have been performed in the first trimester, in time for suction termination of pregnancy if requested.

Table 2 shows that over half of the couples at risk for SS disease, about half of those at risk for $\mathrm{Hb} \mathrm{S} / \beta$ thalassaemia, and only a small proportion of those at risk for haemoglobin SC disease requested prenatal diagnosis. Eight of 14 couples, who were at $50 \%$ risk because one partner had sickle cell disease, requested it.

More people of African than of Afro-Caribbean origin chose prenatal diagnosis (table 3 ).

Table 1 Referrals for counselling for prenatal diagnosis of sickle cell disease by year (170 couples with 188 pregnancies).

\begin{tabular}{lcccc}
\hline Year & $\begin{array}{c}\text { At risk } \\
\text { referrals }\end{array}$ & $\begin{array}{c}\text { Not having PND } \\
\text { (women) }\end{array}$ & $\begin{array}{c}\text { PND requested } \\
\text { (pregnancies) }\end{array}$ & $\begin{array}{c}\text { PNDs completed before } \\
\text { end of 13th week }\end{array}$ \\
\cline { 3 - 5 } & & No & $\%$ \\
\hline
\end{tabular}

\begin{tabular}{lrrrrr}
\hline 1979 & 3 & 1 & 2 & & \\
1980 & 5 & 2 & 3 & & \\
1981 & 2 & 0 & 2 & $2)$ & \\
1982 & 10 & 6 & 4 & $1)$ & \\
1983 & 3 & 0 & 3 & $7)$ & 53 \\
1984 & 16 & 3 & 13 & $1)$ & \\
1985 & 7 & 4 & 3 & $7)$ & 64 \\
1986 & 16 & 7 & 9 & 9 & 86 \\
1987 & 19 & 5 & 14 & 12 & 80 \\
1988 & 26 & 12 & 23 & 16 & 86 \\
1989 & 43 & 23 & 22 & 74 & 68 \\
1990 & 38 & 16 & $(89$ women $)$ & & \\
Total & 188 & 79 & & & \\
& & & & & \\
\hline
\end{tabular}

$\mathrm{PND}=$ prenatal diagnosis

Table 2 Nature of risk and choice of PND.

\begin{tabular}{lccc}
\hline \multirow{2}{*}{ Risk of fetus } & No of couples seen & \multicolumn{2}{c}{ Choosing PND } \\
\cline { 3 - 4 } & & No & $\%$ \\
\hline SS* & 121 & 70 & 58 \\
S $\beta$ thal & 17 & 8 & 47 \\
SC & 18 & 3 & 17 \\
$50 \%$ risk & 14 & 8 & 57 \\
Total & 170 & 89 & 52 \\
\hline
\end{tabular}

* Includes two cases of SD.

$S S v S / \beta$ thal $\chi^{2}=0.24, p=N S$.

SS $v$ SC $\chi^{2}=10 \cdot 26, p=<0.01$.

Table 3 Ethnic group and choice of PND.

\begin{tabular}{lccccc}
\hline & \multicolumn{4}{c}{ Ethnic group } & \multirow{2}{*}{ Total } \\
\cline { 2 - 5 } & Afro-Caribbean & Mixed & African & Other* & \\
\hline No & 45 & 9 & 107 & 9 & 170 \\
Choosing PND & $16 \dagger$ & 4 & $61 \dagger$ & 8 & 89 \\
$\%$ choosing PND & 36 & 44 & 57 & 89 & 52 \\
\hline
\end{tabular}

Mixed $=$ Afro-Caribbean $\times$ African.

* Mostly Cypriots or Indians.

$+\chi^{2}=5.65, \mathrm{p}<0.02$.
'Others' were mostly of Cypriot or Indian origin, most were at risk for $\mathrm{Hb} \mathrm{S} / \beta$ thalassaemia, and most chose this option.

Table 4 shows that $94 \%$ of referred women who already had one or more children with sickle cell disease chose prenatal diagnosis and most terminated the pregnancy when sickle cell disease was diagnosed. Uptake was lower among couples without a previous affected child, and lowest among primigravidae.

Table 5 summarises the women's previous obstetric history (before counselling at our centre or any prenatal diagnosis). There was no clear evidence that any factor other than the presence of a previous affected child was influential.

Table 6 shows the effect of the stage of gestation at referral (this information was available for only 68 of the 81 women who declined prenatal diagnosis). Prenatal diagnosis was requested in $82 \%$ of pregnancies in which the mother was first seen before 13 weeks' gestation, and in $49 \%$ of those in which the mother was first seen in the second trimester. In $6 \%$ of cases, the woman was first seen too late in pregnancy for this option to be offered at all

\section{Discussion}

Sickle cell disease represents a range of genetic conditions of 'intermediate' severity, in which the choice of informed couples for or against prenatal diagnosis using available technology is more or less evenly balanced. It therefore holds particular interest for research on social aspects and this study confirms its value, as it may be seen as a sensitive indicator of factors affecting service acceptability.

At risk couples referred for counselling to the UCH Perinatal Centre are first identified either by screening in antenatal clinics (prospectively), or because they already have an affected child (retrospectively). Most are first informed of their genetic risk by medical or obstetric staff, or by a haemoglobinopathy counsellor in districts where these are available, and many declining the offer of prenatal diagnosis at this stage may not be referred onwards. Thus, though about $50 \%$ of couples seen by us request prenatal diagnosis, the unbiased uptake by informed couples in London is certainly lower, probably around $30 \% .^{78}$ Despite this selection, analysis of the data on all couples counselled at a single prenatal diagnosis centre permits investigation of factors affecting choices.

Midtrimester prenatal diagnosis for sickle cell disease has been available since $1977 .^{9}$ However, the data from our centre and national data (Modell et al, in preparation) show that demand was insignificant until, 10 years ago, prenatal diagnosis became available before 12 weeks of pregnancy. ${ }^{1011}$ The pronounced effect of stage of gestation on uptake of fetal testing observed here confirms the greater acceptability of first trimester prenatal diagnosis. However, carrier screening is still done primarily in antenatal clinics, and most couples at risk are identified too late for the 
Table 4 Effect of parity and previous child with sickle cell disease on choice of PND and termination of affected pregnancy.

\begin{tabular}{|c|c|c|c|c|}
\hline & \multicolumn{2}{|c|}{ Prospectively detected women (no SCD child) } & \multirow{2}{*}{$\begin{array}{l}\text { Women with } 1 \\
\text { or more SCD } \\
\text { children }\end{array}$} & \multirow[b]{2}{*}{ Total } \\
\hline & Primigravidae & Previous pregnancy & & \\
\hline $\begin{array}{l}\text { No of women } \\
\text { Choosing PND } \\
\text { No }(\%)\end{array}$ & $\begin{array}{l}41 \\
15(37)\end{array}$ & $\begin{array}{l}93 \\
43(46)\end{array}$ & $\begin{array}{l}34 \\
32(94)\end{array}$ & $\begin{array}{l}168 \\
89(53)\end{array}$ \\
\hline $\begin{array}{l}\text { Diagnosis, } \\
\text { fetus affected }\end{array}$ & 4 & 14 & 15 & 33 \\
\hline $\begin{array}{l}\text { Termination of } \\
\text { pregnancy }\end{array}$ & 2 & 12 & 14 & 28 \\
\hline
\end{tabular}

Table 5 Previous obstetric history (primigravidae excluded): percent outcome of conceptions.

\begin{tabular}{lccc}
\hline & Couples having PND & & Couples not having PND \\
\cline { 2 - 2 } & $\begin{array}{c}75 \text { women, } \\
116 \text { conceptions (\%) }\end{array}$ & & $\begin{array}{c}50 \text { women, } \\
124 \text { conceptions (\%) }\end{array}$ \\
\hline SCD live births & 31 & 4 \\
Unaffected live births & 33.5 & 48 \\
Terminations (not for SCD) & 21.5 & 23 \\
Miscarriages & 10 & & 18.5 \\
Stillbirth, neonatal death, etc & 4 & 6.5 \\
\hline
\end{tabular}

Table 6 Influence of gestational age at counselling on uptake of PND.

\begin{tabular}{lccc}
\hline \multirow{2}{*}{$\begin{array}{l}\text { Gestation when woman } \\
\text { first seen }\end{array}$} & No & \multicolumn{2}{c}{ Requested PND } \\
\cline { 3 - 4 } & & No & $\%$ \\
\hline Before 13 weeks & 76 & 62 & 82 \\
13-22 weeks & 85 & 42 & 49 \\
Too late for PND & 11 & - & - \\
Total & 172 & 84 & 49 \\
\hline
\end{tabular}

offer of first trimester prenatal diagnosis, and some too late to be offered it at all. There is at present some controversy on how carrier screening for autosomal recessive disorders should be offered; for example, Wald ${ }^{12}$ considers screening in the antenatal clinic to be ideal, as "the best results are obtained by delaying carrier screening until the latest time when effective preventing action can be taken". Our findings indicate the limitations of antenatal screening, and strongly support the Royal College of Physicians' ${ }^{1}$ recommendation that screening for risk of inherited disease should also be provided before pregnancy, in primary health care when possible.

The increasing availability of correct information also has a strong effect on demand for prenatal diagnosis for sickle cell disease. Before 1988, at risk couples detected in antenatal clinics were counselled by untrained medical or nursing staff, and our records show that the information given was often incomplete, incorrect, or poorly understood. Since 1988 the at risk couples we see are increasingly well informed, as more have already seen a trained haemoglobinopathy counsellor.

Direct experience of sickle cell disease within the family is also important; over $90 \%$ of the women we saw who already had an affected child chose prenatal diagnosis. Some of the children were severely affected but many were doing well: their mothers said they could not cope with the increased anxiety associated with having two affected children. These mothers may represent a highly selected sample, as parents with affected children should in theory be well informed and only those who knew they wanted prenatal diagnosis may have been referred. However, our notes show that by no means all of them had been informed that prenatal diagnosis was available by the doctor looking after their child; some had learnt about it from a sickle cell centre, a health visitor, or a friend or other non-medical source.

The fact that half of the couples we saw where one partner actually had sickle cell disease chose prenatal diagnosis shows the ethical point that services for avoiding genetic disorders may also be used by people who have a genetic disorder themselves.

Ethnic group is also an important determinant; fewer couples of Afro-Caribbean than of African extraction requested prenatal diagnosis. The ethnic distinction is also one of social class, as many African couples are in the UK to complete advanced studies. In addition, most plan to return to Africa, where the risks associated with sickle cell disease are greatest. Most at risk couples of Cypriot or Mediterranean origin request prenatal diagnosis and terminate affected pregnancies, regardless of the stage of gestation at which they are seen.

We expected that factors in the obstetric history, such as the number of previous medical abortions, miscarriages, stillbirths, or neonatal deaths, would influence choice, but there was little evidence for this. However, primigravidae were least likely to request prenatal diagnosis.

All couples declining prenatal diagnosis said they were pleased they had been informed of their risk and requested a neonatal diagnosis. Consistent with the observed high rate of induced abortion in the group's previous obstetric history, an absolute objection to termination of pregnancy was rarely given as a reason for declining prenatal diagnosis. Many of the women would not consider terminating the current pregnancy because of sickle cell disease, but would have liked to know the diagnosis: they were deterred by the risk to the pregnancy. A second common reason given for declining prenatal diagnosis was fear of the procedure. Though only a few couples declined on religious grounds, it is possible that most with strong religious views had chosen not to be referred.

The partner was unknown or unavailable in three cases. When the woman is a carrier, the chance that her partner is also a carrier is $12 \%$ if he is Afro-Caribbean and $25 \%$ if he is African, so there is usually a 3 to $6 \%$ risk that the woman is actually carrying an affected fetus. It is important to inform the woman of this risk, and advisable to offer prenatal diagnosis if she is interested. Two of these carrier women expressed concern about the genetic risk, none requested prenatal diagnosis, and all requested a neonatal diagnosis. 
We thank Dr Elizabeth Anionwu for constructive criticisms, and Dr John Old, who did most of the DNA analyses for first trimester prenatal diagnosis in these cases.

1 Royal College of Physicians. Prenatal diagnosis and genetic The Royal College of Physicians of London, 1989.

2 British Society for Haematology. Guidelines for haemoglobinopathy screening. Clin Lab Haematol 1988;10:87-94.

3 Petrou M, Brugiatelli M, Old J, Ward RHT, Kwai Peng Wong, Modell B. Alpha thalassaemia hydrops fetalis in the UK: the importance of screening pregnant women of Chinese or other South East Asian or Mediterranean extraction for alpha thalassaemia trait. Br $\mathcal{f}$ Obstet Gynaecol (in press).

4 Modell B, Ward RHT, Fairweather DVI. Effect of introducing antenatal diagnosis on the reproductive behaviour of families
5 Serjeant GR. Sickle cell disease. 3rd ed. Oxford: Oxford University Press, 1992.

6 Davies SC, Brozovic M. The presentation, management and prophylaxis of sickle cell disease. Blood Rev 1989;5:1and 16.

7 Anionwu EN, Patel N, Kanji G, Renges H, Brosovic $M$. Counselling for prenatal diagnosis of sickle cell disease and $\beta$ thalassaemia major: a four year experience. $\mathcal{f} \mathrm{Med}$

Genet 1987;25:769.
8 Rowley PT, Loader S, Walden M. Pregnant women identified as haemoglobinopathy carriers by prenatal screening want genetic counseling and use information provided. Birth Defects 1988;23(5B):449-54.

9 Fairweather DVI, Modell B, Berdoukas V, et al. Antenatal diagnosis of thalassaemia major. BMF 1978;i:350-3.

10 Old JM, Ward RHT, Petrou M, Karagozlu F, Modell B Weatherall DJ. First-trimester fetal diagnosis for the haemoglobinopathies: three cases. Lancet 1982;ii:1413-6. 11 Old JM, Fitches A, Heath C, et al. First trimester fetal diagnosis for the haemoglobinopathies: report on 200 cases. Lancet 1986;ii:763-6.

12 Wald NJ. Couple screening for cystic fibrosis. Lancet 1991;338:1318-9. 